\title{
ABORDAGEM SOBRE O CONHECIMENTO SALVO: EXCELÊNCIA ACADÊMICA, CONSTRUÇÃO HUMANA E MECANISMOS DA MEMÓRIA
}

\author{
Layla Rosa Maciel Pereira ${ }^{1}$ \\ Anderson Silva ${ }^{2}$
}

Resumo: Esta pesquisa objetiva discutir a interligação das conexões nervosas modeladas às experiências sensoriais cotidianas, a construção humana e funções executivas estruturadas a partir da primeira infância, gradativamente desenvolvidas, relacionando o comportamento e a atividade cerebral. Justifica-se este trabalho pelo interesse em buscar arcabouços teóricos, tais como: neurociência, neuropsicologia, neurolinguística e pedagogia para auxiliarem os profissionais da educação a informar os discentes quanto às funções cognitivas superiores: atenção, percepção, linguagem, memória e demais aplicabilidades no processo de ensino/aprendizagem. Em termos metodológicos, por meio de um mapa conceitual desenvolvido por uma estudante de dezessete anos, foi feita análise associativa, emocional e resposta da memória, como instrumento de estudo ao interpretar a validade do conhecimento adquirido. Levando-se em conta o que foi observado, a consolidação de informações é influenciada pela seleção prévia, estímulo, experiência sensorial, canal de aprendizagem, método comunicativo, além do processo solitário e ativo do recordar.

Palavras-chave: Funções executivas; Atividade cerebral; Ensino; Aprendizagem.

\footnotetext{
1 Escola Estadual de Ensino Médio Integral Professor Nelson do Nascimento Monteiro / Rua Hermenegildo Scarensi, 91, Conjunto Residencial 31 de Março, São José dos Campos - SP, Brasil. E-mail: laylarosanp@gmail.com.

2 Pontifícia Universidade Católica de São Paulo (PUC-SP/LAEL). Secretaria da Educação do Estado de São Paulo (SEE-SP). Escola Estadual de Ensino Médio Integral Professor Nelson do Nascimento Monteiro / Rua Hermenegildo Scarensi, 91, Conjunto Residencial 31 de Março, São José dos Campos - SP, Brasil, E-mail: andcs23@hotmail.com.
} 